\title{
Cushing's syndrome managed by endoscopic ultrasound-guided radiofrequency ablation of adrenal gland adenoma
}

A 38-year-old woman presented with "moon face," "buffalo hump," and weight gain of $9 \mathrm{~kg}$ in 12 months. Overnight, $1 \mathrm{mg}$ dexamethasone failed to suppress the morning level of cortisol, and the 24-hour urine cortisol level was elevated to $101 \mu \mathrm{g} /$ day (normal range $0-50)$. Initial contrast-enhanced abdominal computed tomography (CT) showed a $2.8-\mathrm{cm}$ left adrenal mass enhanced in arterial phase, and the patient was diagnosed with Cushing's syndrome due to left adrenal adenoma ( $\boldsymbol{\nabla}$ Fig. $\mathbf{1}$ a). She refused surgical treatment but agreed to undergo endoscopic ultrasound-guided radiofrequency ablation (EUS-RFA; STARmed, Koyang, Korea) ( Video 1).

Prior to RFA, contrast-enhanced EUS with SonoVue (Bracco, Inc., Milan, Italy) was performed. Findings of early enhancement and delayed washout were compatible with adrenal adenoma ( $\boldsymbol{F}$ Fig. $\mathbf{2 a}$ a).

A 19-guage needle electrode was positioned inside the adenoma. Using realtime EUS imaging, RFA ( $50 \mathrm{~W}$ ) was performed at five different sites ( $\mathbf{F i g .} \mathbf{2} \mathbf{b}$ ). Four days later contrast-enhanced EUS revealed viable tissue remaining at the marginal edge of the previously ablated portion of the adenoma ( $\mathbf{F i g . 3 a}$ ). EUS-RFA was repeated at five more sites in the remaining viable tissue ( $\triangleright$ Fig. $\mathbf{3} \mathbf{b}$ ). Follow-up CT at 1 week showed the adrenal mass almost completely replaced with necrotic tissue, without complications ( $\triangleright$ Fig. $\mathbf{1} \mathbf{b}$ ). Serum and urine cortisol levels returned to normal the following day and remained normal for the next 2 months, with no adverse events related to RFA. However after the third month, the cortisol levels were re-elevated and this time the patient agreed to surgery.

Until recently, there were only a few case reports of RFA for the treatment of Cushing's syndrome; all of them were treated via the $\mathrm{CT}$-guided percutaneous method $[1,2]$. The present case is the first in
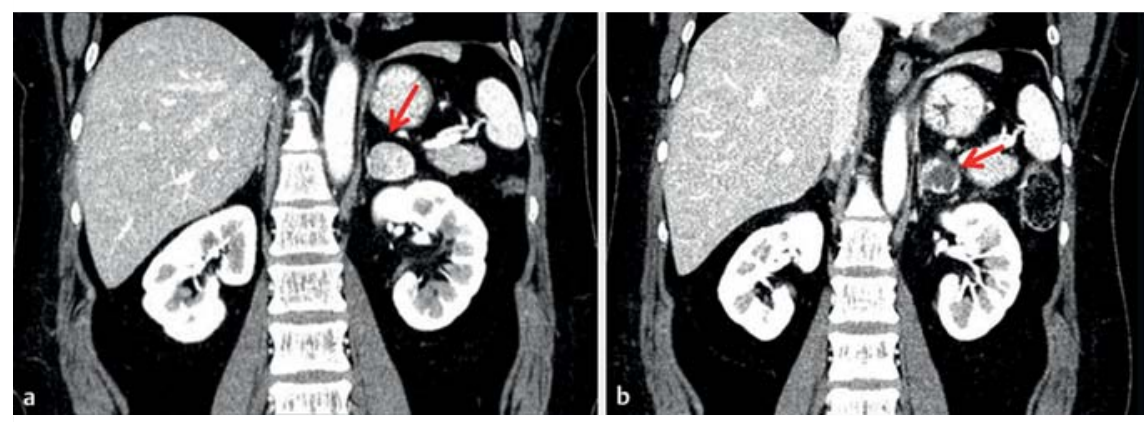

- Fig. 1 Computed tomography scan showing a $2.8-\mathrm{cm}$ left adrenal adenoma with arterial enhancement in the coronal view (arrows). a Before endoscopic ultrasound-guided radiofrequency ablation (EUS-RFA). b After EUS-RFA.

which EUS-RFA was used to manage Cushing's syndrome caused by adrenal adenoma. This case report supports EUS-RFA as a safe and feasible alternative method that should be considered in patients who refuse surgical treatment. Further evidence and experiences are required.

Endoscopy_UCTN_Code_TTT_1AS_2AD

\section{Competing interests}

None

\section{The Authors}

Sun-Ho Lee, Dong Wan Seo, Dongwook Oh, Tae Jun Song, Do Hyun Park, Sang Soo Lee, Myung-Hwan Kim

Division of Gastroenterology, Department of Internal Medicine, Asan Medical Center, University of Ulsan College of Medicine, Seoul, Korea 

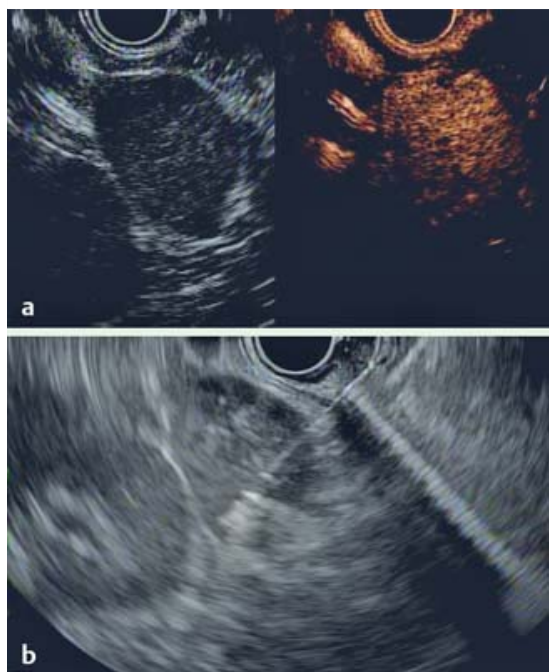

Fig. 2 Endoscopic ultrasound-guided radiofrequency ablation (EUS-RFA) of the left adrenal adenoma. a Contrastenhanced EUS with early enhancement. b The EUS-RFA needle positioned inside the adenoma.
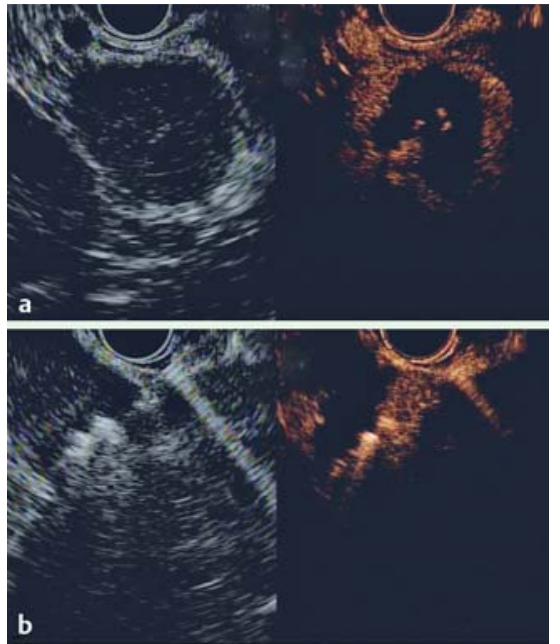

- Fig. 3 Contrast-enhanced endoscopic ultrasound (EUS) 4 days after the first EUSguided radiofrequency ablation (RFA) treatment. a Central hypo-echogenicity with enhancement remained at the marginal edge of the adenoma. $\mathbf{b}$ Repeat EUSRFA was performed.
Corresponding author

\section{Dong Wan Seo, MD, PhD}

Division of Gastroenterology, Department of Internal Medicine, Asan Medical Center, University of Ulsan College of Medicine, 88, Olympic-Ro 43-Gil, Songpa-gu, Seoul 138-736, Korea,

Fax: +82-2-4855782,

dwseoamc@amc.seoul.kr

\section{References}

[1] Nishi N, Tanaka J, Minagawa A. Cushing syndrome treated by radiofrequency ablation of adrenal gland adenoma. Jpn J Radiol 2012; 30: $274-276$

[2] Nunes TF, Szejnfeld D, Xavier AC et al. Percutaneous ablation of functioning adrenal adenoma: a report on 11 cases and a review of the literature. Abdom Imaging 2013; 38: $1130-1135$

\section{Bibliography}

DOI http://dx.doi.org/10.1055/s-0042-118165

Endoscopy 2017; 49: E1-E2

(c) Georg Thieme Verlag KG Stuttgart · New York ISSN 0013-726X 